\title{
LA FORMACIÓN DE SUJETOS SOCIALES EN LA ESCUELA
}

\section{JAIRO HERNANDO GÓMEZ ESTEBAN}

\section{Resumen}

El presente artículo intenta desarrollar una teoría sobre el aprendizaje cívico. Asumiendo de entrada las limitaciones y sesgos de las teorías psicológicas del aprendizaje y apoyándose en algunas teorías sociales (Bourdieu, Giddens y Wenger) se busca plantear, primero, una teoría social del aprendizaje, para luego discutir las diversas formas de comprensión de la ciudadanía por parte de las tres tradiciones normativas de la filosofía política (liberalismo, comunitarismo y republicanismo) así como de los desafíos teóricos que el concepto moderno de ciudadanía presenta (feminismo, poscolonialismo, teoría crítica de la raza y movimientos sociales). Con base en la integración de estos dos problemas, se formulan los presupuestos conceptuales y metodológicos para una teoría del aprendizaje cívico.

\section{Palabras clave}

Teoría social del aprendizaje, ciudadanía, liberalismo, comunitarismo, republicanismo, aprendizaje cívico, competencias sociales, autoreferencialidad, descentración.

\section{Abstract}

The present article pretends to develop a theory about the civic learning. It suppose from the beginning the limitations and the slants of the learning psychological theories and with the support of some social theories (Bourdieu, Giddens y Wenger) it search in the first place, a social learning theory and then, discuss the different ways of understand the citizenship from the three normative traditions from the political philosophy (liberalism, communitarism and republicanism) just as the theoretical challenge that the modern concept of citizenship brings (feminism, pos-colonialism, the critical theory of the race and social movements). On the basis of the integration of this two problems, it is formulate the conceptual and methodological presuppositions for a civic learning theory.

\section{Key words}

Learning social theory, citizenship, liberalism, communitarism, republicanism, civic learning, social competences, self-reference, descentration. 


\title{
LA FORMACIÓN DE SUJETOS SOCIALES EN LA ESCUELA *
}

\section{JAIRO HERNANDO GÓMEZ ESTEBAN ${ }^{153}$}

\begin{abstract}
¿Cuál es el garante último de mis decisiones cuando lo he perdido todo, cuando estoy desorientado, dominado, tanto externa como internamente? ¿ Queda algo que sustituya a Dios, al Hombre, a la Historia o a la Razón? Siempre le he dado la misma respuesta: el deseo de singularidad, de individuación, el deseo de hacer de mi vida una historia personal. Hoy, en este mundo socializado, colectivizado, masificado, mi último recurso es mi singularidad, mi voluntad de ser singular.
\end{abstract}

Alain Touraine

A la búsqueda de sí mismo

La enseñanza de las ciencias sociales en la escuela colombiana está atravesando uno de sus mayores retos y encrucijadas de toda su historia ${ }^{154}$. Entre sus grandes desafíos podemos destacar los siguientes: a) la formación de ciudadanos híbridos y plurales, b) el desarrollo del pensamiento social (mentes sociales) que tensione lo universal y lo local, lo global y lo nacional y, c) la comprensión y asunción de la "apertura" de las ciencias sociales hacia nuevos lugares de enunciación de "lo social" que incorpore las nuevas formas de hibridación de saberes, las prácticas sociales y los dominios del conocimiento social .

Entre sus grandes encrucijadas podemos destacar: a) la transformación estructural, tanto a nivel administrativo como pedagógico, que subyace a la implementación de los nuevos lineamientos curriculares y los estándares; b) el cambio de actitud y representación social que administrativos (rectores y consejos académicos), padres de familia, docentes, y por derivación, estudiantes, tienen de las ciencias sociales y su "utilidad práctica". No se puede seguir creyendo que las ciencias sociales escolares tienen la función de transmitir una "cultura general", conocer la "historia patria", desarrollar "valores" o formar "personas críticas", objetivos que se han vaciado de contenido y c) la articulación de los proyectos del área o macroproyectos emanados de ONGs, alcaldías, Secretarías de Educación, MEN o entidades privadas interesadas en cualquier forma de desarrollo social y cultural y transformación de prácticas sociales.

Los nuevos lineamientos curriculares de ciencias sociales intentan, de alguna manera, incorporar estos desafíos recurriendo a conceptos como transdisciplinariedad y currículo integrado. No obstante, el problema de la constitución de sujetos sociales a la luz de estos lineamientos queda sin resolver. El propósito de este artículo es profundizar y tematizar este proceso de formación de sujetos en la escuela, teniendo como marco de referencia los lineamientos curriculares

\footnotetext{
* Artículo recibido en agosto 19 de 2003 y arbitrado en septiembre 19 de 2003

${ }^{153}$ Profesor Titular Universidad Distrital Francisco José de Caldas, correo : jairogo40@hotmail.com

${ }^{154}$ Para una breve historia de la enseñanza de las ciencias sociales en Colombia, véase GÓMEZ, E. Jairo $\mathrm{H}$., La construcción del conocimiento social en la escuela, Bogotá, Universidad Distrital, Centro de Investigaciones, capítulo III, 2002.
} 
De entrada es preciso aclarar dos aspectos: i) la interdisciplinariedad y sus derivados (trans-multi, pluri, etc.) no se plantea porque se hayan acabado las disciplinas o hayan colapsado o cualquier otra cosa, sino por la necesidad de establecer correlaciones, interdependencias o bisagras conceptuales que vayan más allá de la simple yuxtaposición de definiciones frente a la complejidad de los fenómenos físicos y sociales y, sobre todo, ante la necesidad de entender las interrelaciones entre los diversos niveles de organización de la vida; y ii) desde el punto de vista escolar, la interdisciplinariedad y sus derivados surgen como presupuesto epistemológico de un modelo curricular integrado que ante todo se opone al currículo asignaturista, lineal y fragmentario que atomiza el conocimiento social en definiciones y teorías deshilvanadas y estatizantes, con una profunda carga ideológica y de sentido común.

La exigencia interdisciplinaria, o al menos la necesidad de combinar los conceptos o teorías de dominios o saberes particulares del conocimiento, para resolver problemas, ya sean muy generales o ya sean muy complejos, se remonta a los orígenes mismos del saber en Occidente (en Oriente el sincretismo entre ciencia, filosofía y religión vuelve irrelevante esta problemática).

La paideia griega y particularmente el programa de los sofistas de una enkuklios paideia se puede entender, en términos generales y con todos los supuestos filosóficos que conlleva, como un programa para una educación que desarrolle lo que hoy llamamos la cultura; es decir, una educación que le apunta a los ideales de la Verdad (la Ciencia), la Belleza (la Estética) y la Justicia (la Ética y la Política). Este propósito, que no sólo era educativo sino antropológico y espiritual, suponía no sólo una cosmovisión del hombre que lo ubicaba como "medida de todas las cosas" (Protágoras), y que Jaeger denomina orgánica porque en ella las partes son consideradas como miembros de un todo, sino que se sustentaba en uno de los mayores logros de la cultura helénica: el humanismo ${ }^{155}$.

El espíritu de la paideia de alguna manera se mantuvo durante la educación medieval mediante la integración y articulación entre las artes y las ciencias que el trivium (gramática, retórica y dialéctica) y el quadrivium (aritmética, geometría, astronomía y música) se propusieron. Esta necesidad de integrar y relacionar en un todo dinámico va a ser retomada en el siglo XVII por Leibniz con la Monadología y por Comenio con su pedagogía de la unidad, la pansophia.

En el siglo XVIII, los enciclopedistas van a asumir el proyecto de saber total como uno de sus objetivos centrales. En efecto, la Enciclopedia, dirigida por Diderot, trataba no simplemente de unir en un todo los conocimientos existentes, sino ligarlos de manera que permitiera comprender las nuevas formas de relaciones sociales que se estaban generando, así como sus recientes expresiones culturales y políticas que fueran tan agudamente satirizadas por Voltaire.

En el siglo XIX, probablemente la mayor tentativa de integrar el conocimiento a través de unos principios generales sea la obra maestra de Alexandre de Humboldt, Kosmos, cuyo título ya es suficientemente ilustrativo sobre las metas que se proponía alcanzar.

Estos hitos históricos podrían atestiguar que la búsqueda de una "unidad de saber" como diría Morin, ha sido una constante epistemológica, y que la reivindicación interdisciplinaria que actualmente se reclama no es más que la reafirmación de una integridad perdida. El proyecto de la unidad del conocimiento (ya sea como sabiduría, filosofía o interdisciplinariedad) se hace más necesario en la medida en que el saber más se

\footnotetext{
155 JAEGER, W., Paideia: Los ideales de la cultura griega, Fondo de Cultura Económica, México, 1992. 
especializa. Esta dialéctica de la unidad de la especialización posibilita establecer las relaciones recíprocas de los fenómenos que pertenecen a diversos campos de la realidad tanto física como social y, así mismo, garantiza la independencia relativa de los métodos de las estructuras epistemológicas de las disciplinas; es decir, de aplicar los métodos de una disciplina, tal como son, o con algunas modificaciones, a otras disciplinas.

Para Dogan y Pahre (1995), la especialización es inevitable, y es en las fronteras de esta especialización en donde se produce la intersección de dos o más disciplinas. La especialización conserva su importancia, porque ofrece un centro de interés. "Cada disciplina ilumina un conjunto de variables, debido precisamente a que los demás factores son percibidos como externos, alejados y de igual relevancia. Tal simplificación analítica es fundamental al principio para clarificar y explorar ciertas relaciones causales. Los diferentes tipos de razonamiento causal desarrollados por las distintas disciplinas pueden aprovecharse mejor, si se les combina prudentemente para tratar de captar la abundancia de factores existentes en el mundo real." 156

De esta forma, retomando y recombinando los resultados de las teorías y métodos más especializados de las ciencias sociales (principalmente de las que ellos denominan subdisciplinas como la psicología social, la filosofía política o la sociología cultural), estos autores introducen la noción de hibridación la cual permite emplear un concepto de una disciplina para describir un fenómeno nuevo que pueda tener consecuencias en otras disciplinas (v. gr. el concepto de "matriarcado" original de la etnología ha sido retomado y en algunos casos aprobado por la sociología de la familia, la demografía, la historia y muchas otras disciplinas más.

Esta manera de entender la hibridación, evidentemente que se adecua mucho más al trabajo pedagógico de las Ciencias Sociales, ya que sin perder la estructura conceptual especializada de las disciplinas, y exigiendo una permanente actualización de esas fronteras a los docentes, posibilita desplazamientos conceptuales y metodológicos, que son los que reclama un currículo integrado.

Sin embargo, para las condiciones culturales y políticas de un país como Colombia, se hace necesario incorporar la perspectiva cultural que García Canclini le confiere a la hibridación. En efecto, en su importante trabajo sobre Culturas híbridas, García Canclini prefiere este término a otros como sincretismo o mestizaje porque "abarca diversas mezclas interculturales -no sólo las raciales a las que suele limitarse "mestizaje"- y porque permite incluir las formas modernas de hibridación mejor que "sincretismo", fórmula referida casi siempre a fusiones religiosas o de movimientos simbólicos tradicionales."157 Por tanto, creemos que la hibridación no debe reducirse a las formas de recombinación y fusión disciplinar, sino que debe ampliarse a las formas como las ciencias sociales se relacionan y se fusionan con los saberes y prácticas sociales y culturales circulantes en los diversos escenarios públicos. En consecuencia, preferimos hablar más de una hibridación de saberes que de interdisciplinariedad o hibridación disciplinar.

Desde esta perspectiva, sobre las relaciones entre saberes disciplinares es que pretendemos abordar el análisis de la constitución de sujetos sociales en la escuela, y en particular desde el papel que los nuevos lineamientos curriculares cumplen en esta tarea.

\footnotetext{
${ }^{156}$ DOGAN, M.; PAHRE, R., Las nuevas ciencias sociales y la marginalidad creadora, Grijalbo, México, 1993.

${ }^{157}$ GARCIA CANCLINI, Néstor, Culturas híbridas. Estrategias para entrar y salir de la modernidad,. Consejo Nacional para la Cultura y las Artes, Grijalbo, México, 1989.
} 


\section{El sujeto social escolar}

La formación de sujetos sociales, no sólo como objetivo del MEN, sino de cualquier política educativa, debe apuntar básicamente en tres direcciones: a) el aprendizaje de unos saberes o ámbitos del conocimiento social; b) el desarrollo y potencialización de procesos de interacción en unos dominios o campos sociales y, c) la promoción de prácticas sociales y culturales con un horizonte ético-político plural y democrático. En otras palabras, la formación de sujetos pasa por lo cognitivo, lo volitivo y lo praxiológico: tres dimensiones que deben verse englobadas en un marco cultural y político determinado.

¿Qué papel juegan los nuevos lineamientos curriculares de ciencias sociales en la consecución de estos propósitos? Veamos, de manera sucinta, la organización y presupuestos de estos lineamientos, para desde allí, presentar nuestros planteamientos y eventuales aportes para la fundamentación de una teoría sobre la formación de sujetos sociales en la escuela.

EI MEN propone que estos lineamientos se aborden a través de:

- Ejes generadores

- Preguntas problematizadoras

- Ámbitos conceptuales

- Desarrollo de competencias

- Con una estructura flexible, abierta, integrada y en espiral

Veamos qué significa cada uno de estos aspectos. "Los ejes generadores pueden caracterizarse como una selección o agrupación temática importante que se ha hecho de la realidad social pasada-presente, en torno a la cual se aglutinan ideas, conceptos, temas, problemas, hechos y objetos que enmarcan y organizan la esencia de cada disciplina (en estos lineamientos cada eje podría referirse en mayor grado a una disciplina de las ciencias sociales). La gran fortaleza de los ejes generadores es su globalidad; es decir, ofrecen perspectivas amplias para abordar las ciencias sociales, ayudando a estructurar una visión general de las problemáticas sociales, en las y los estudiantes.

Las preguntas problematizadoras, como su nombre lo dice, son preguntas que plantean problemas con el fin, no sólo de atraer la atención de las y los estudiantes -porque se esbozan de forma llamativa o interesante-, sino que, su principal objetivo es fomentar la investigación constante y generar nuevos conocimientos en la clase. Podría decirse que ellas son "motores" que impulsan la búsqueda y creación de un nuevo saber en el aula.

En los ámbitos conceptuales se ha denominado ámbitos conceptuales en esta propuesta curricular, a la dimensión donde se agrupan varios conceptos fundamentales de las ciencias sociales, que ayudan a investigar y "resolver" las preguntas problematizadoras. Partiendo de los anteriores puntos, los ámbitos conceptuales, y por ende los conceptos fundamentales, se seleccionaron bajo los siguientes criterios:

- Pueden y deben ser abordados o enjuiciados desde diversas ciencias sociales.

- Deben estar acorde con los procesos del desarrollo psicogenético de las y los estudiantes, al igual que las competencias.

- Facilitan miradas alternas sobre la realidad, para propiciar transformaciones en todo aquello que impida el desarrollo del individuo y la sociedad. 
- Deben permitir desarrollar un proceso de interrelación y complejidad creciente, para ir acercándose al pensamiento formal propio de la comprensión científica de la sociedad.

En primera instancia, se seleccionaron cinco grandes referentes: Nivel cognitivo, vivencias o experiencias, manejo de conceptos, perspectiva temporal y tiempo histórico, que permanecen durante todo el proceso educativo. En torno a ellos, se estableció la secuencia conceptual del área, y se indica de forma aproximativa, de donde se parte y a donde se espera llegar.

Las competencias son entendidas en un sentido pleno, implican siempre un saber "qué" (significados-conceptos), un saber "cómo" (procedimientos-estrategias), un saber "por qué" (valores-sentidos) y un saber "para qué" (intereses-opciones- creencias).

Desde esta caracterización genérica, los lineamientos distinguen las siguientes competencias para el área de ciencias sociales:

- Competencias cognitivas: están referidas al manejo conceptual y sus aplicaciones en ámbitos y contextos particulares. Dichas aplicaciones se concretan en el contexto social-cultural, y los ámbitos se enmarcan en torno del conocimiento disciplinar. Por tanto, estas competencias son necesarias tanto en el ámbito académico como en el cotidiano para buscar alternativas y resolver problemas.

- Competencias procedimentales: referidas al manejo de técnicas, proceso y estrategias operativas, para buscar, seleccionar, organizar y utilizar información significativa, codificarla y decodificarla. Competencias necesarias para afrontar de manera eficiente la resolución de problemas en diferentes contextos y perspectivas.

- Competencias interpersonales (o socializadoras): entendidas como la actitud o disposición de un individuo para interactuar y comunicarse con otros, y ponerse en el lugar de esos otros, percibiendo y tolerando sus estados de ánimo, emociones, reacciones, etc., -capacidad de descentración-. Todo ello para crear una atmósfera social posibilitante para todas y todos los involucrados en un contexto. Competencias que son vitales para los seres que nos creamos y desarrollamos en sociedad.

- Competencias intrapersonales (o valorativas): entendidas como la capacidad de reflexionar sobre uno mismo, lo cual permite descubrir, representar y simbolizar sus propios sentimientos y emociones.

Y finalmente, el currículo es entendido con una estructura flexible, abierta e integrada.

Flexible, tanto porque un problema o pregunta puede ser estudiado en forma sincrónica o diacrónica en distintos espacios y sociedades, cuanto porque puede afrontarse desde distintas perspectivas disciplinares identificando y contrastando las relaciones que se producen entre ellas.

Abierta, porque permite el análisis y la reflexión seria sobre los problemas críticos que afectan a la humanidad y a la población colombiana; abierta a la reflexión sobre los desafíos que debe afrontar el país y los educandos (como ciudadanos copartícipes de una sociedad nacional y si se quiere, incluso global) en un futuro próximo; abierta porque posibilita el ingreso de temáticas actuales de interés para estudiantes y docentes y desde las cuales se generan, hacia el pasado el presente o el futuro, preguntas que obliguen a replantearse los supuestos que individual o socialmente se manejan como connaturales. 
Integrada, no en el sentido de una integración de las disciplinas científicas que redunde en las áreas curriculares (matemáticas, inglés, sociales, español, etc.), sino de una integración disciplinar intra-área, trabajando con problemas que integren historia, geografía, cívica, economía, sociología antropología, etc.; problemas en los cuales se integren las distintas versiones de las ciencias sociales y humanas."

Ahora bien, si miramos con detenimiento los ocho ejes generadores pueden ser agrupados en tres grandes categorías o dimensiones del conocimiento social: a) Dimensión Ético-Político: (Ejes 1-2-8); b) Dimensión Espacial-ambiental (Ejes 3-4-5) y c) Dimensión Histórico-Cultural (Ejes 6-7). Estas tres dimensiones a su a su vez son coherentes con las competencias sociales (valorativas, cognitivas, socializadoras) que se proponen.

No debemos sorprendernos si estos tres saberes fundamentales del conocimiento social coinciden con las tres grandes formas de explicación que las teorías de las prácticas sociales han formulado. En efecto podemos clasificar estas teorias, obviamente de una manera muy simplificada, de acuerdo a como entienden cada una de ellas la práctica social. En primer lugar, están las Teorías marxistas y neomarxistas que asumen la práctica como el motor de la historia y la generadora de la conciencia social. En segundo lugar, las Teorías estructural-funcionalistas en donde las prácticas sociales configuran el espacio habitado, tensionan las interacciones sociales y generan procesos específicos de representación simbólica; y en tercer lugar, la Teoría de la estructuración en donde la práctica es el ámbito de agenciamiento y puesta en escena de las competencias del sujeto social.

Esta prolongación de las prácticas sociales no es más que la continuidad entre el saber cotidiano y el conocimiento científico, tal como lo propone el "programa fuerte" de la sociología del conocimiento ${ }^{158}$. Sin embargo, es en esta transposición didáctica de saberes sociales en prácticas sociales que se efectúa en la escuela, en donde aparece el sujeto con todas sus mediaciones e implicaciones.

En efecto, entre las prácticas y los saberes sociales el sujeto se va constituyendo mediante su inserción en lo público a través del universo simbólico de significados, leyes y normas que el Estado promueve, y mediatizado por las relaciones de poder en que se encuentra envuelto. En otras palabras, los dominios o campos en los cuales se expresa el sujeto social se dan en lo público, en donde se manifiesta lo visible, se expresan las identidades, el espacio donde se habita y se interactúa; en lo simbólico dado por el universo de significados que el sujeto comparte en sus diversas comunidades de prácticas; y en las relaciones de poder que el Estado, a través de sus diversas instituciones y organizaciones, abroga o reglamenta códigos jurídicos, normas morales o prescripciones o convenciones sociales.

\footnotetext{
${ }^{158}$ En la sociología del conocimiento tradicional existen dos tipos de conocimiento: el de las creencias, los saberes y las representaciones sociales por un lado, y por otro lado, el auténtico conocimiento científico, cuyos orígenes son ciertamente sociales, pero logra independencia y autonomía completa en los juegos de lenguajes propios de las comunidades científicas. Por otra parte, en el denominado "programa fuerte" de la sociología del conocimiento moderno o sociología de la ciencia, el conocimiento científico es tomado como un aspecto cultural más de la sociedad a la par del arte, el saber narrativo o el conocimiento de sentido común, sin conceder de antemano que tenga un estatuto privilegiado. El científico es visto aquí como un miembro mas de la comunidad cuyas herramientas lingüísticas y técnicas fueron construidas por y para esa comunidad y por tanto inseparables del contexto social dentro del que se produjeron. Para mayor profundización en la sociología del conocimiento, remitimos al lector a: OLIVÉ, L., La explicación social del conocimiento, UNAM, México, 1994, y REMMLING, G., Hacia la Sociología del Conocimiento, Fondo de Cultura Económica, México, 1986.
} 


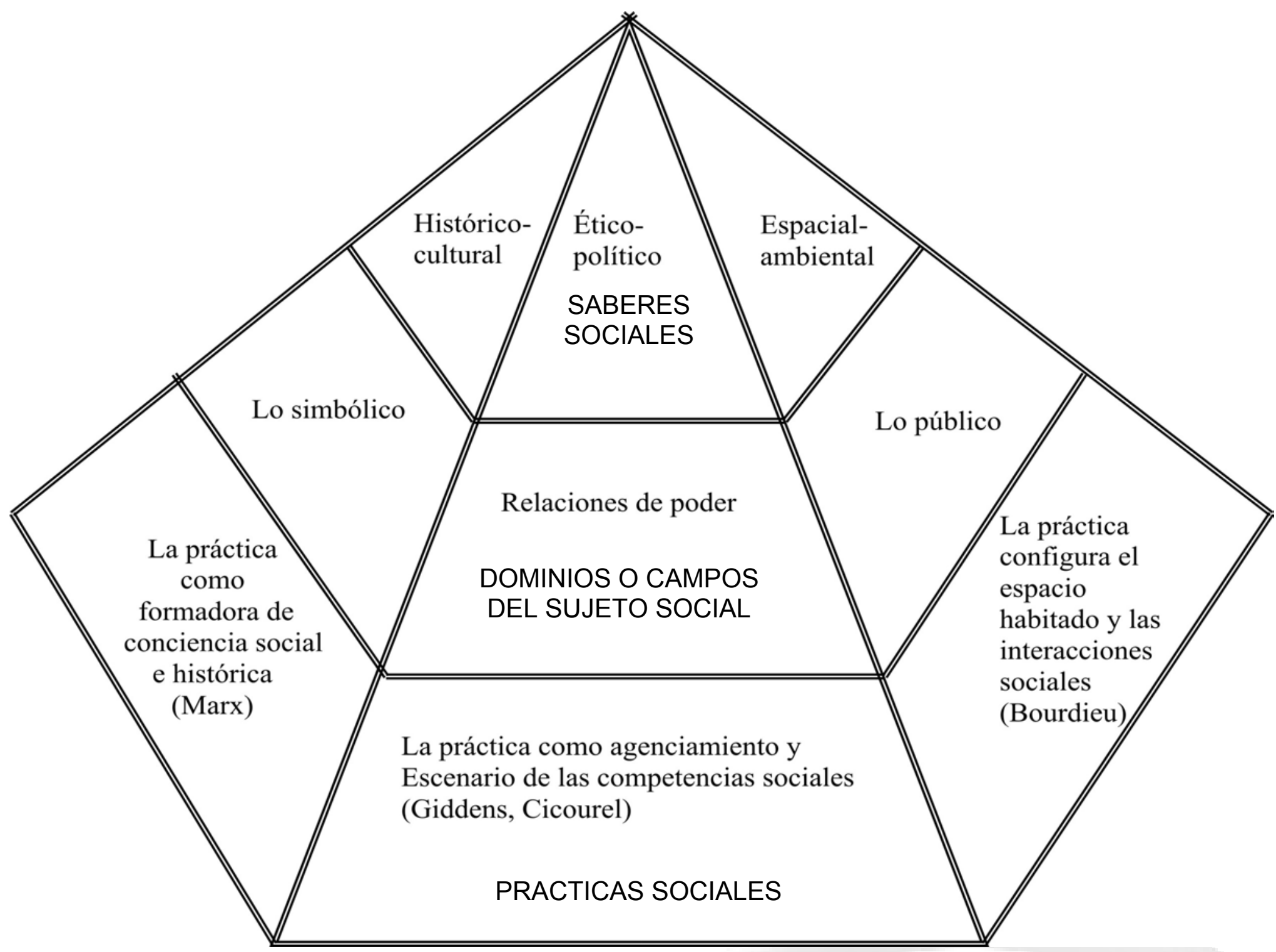

Fuente: El autor

Estos dominios o campos del conocimiento social median, entonces, entre las prácticas y los saberes sociales. Es en estos dominios que se efectúan los procesos de subjetivación (plantearse proyectos individuales y colectivos, voluntad de intervención pública, etc.) y de desubjetivación (descomposición y degradación de sí mismo, incapacidad de centrarse y afirmarse), y es de acuerdo a la posición que el "velo de incertidumbre" ${ }^{159}$ le otorgue, que el sujeto aprenderá y elaborará con mayor o menor complejidad, tanto las prácticas como los saberes sociales. Por tanto, la formación de sujetos sociales debe asumirse como una pirámide que de ninguna manera puede desarticular los tres componentes del proceso.

\footnotetext{
${ }^{159}$ El concepto de "velo de incertidumbre" fue introducido por Rawls para mostrar que los individuos no saben cuál rol o qué lugar ocuparán en la sociedad. Se refiere entonces al momento en que los individuos no saben si van a ser pobres o ricos, con un coeficiente intelectual alto o una inteligencia promedio, poderosos u oprimidos. Es la única noción de bienestar válida, ya que por actuar bajo el "velo de la incertidumbre", es la única que puede propender por el bien común. Véase: RAWLS, J., Teoría de la Justicia, Fondo de Cultura Económica, México, 2000.
} 
La concepción o connotación que cada uno de los autores propuestos le atribuye a las prácticas sociales no tiene que coincidir o corresponder necesariamente con un campo social y, por derivación, generar un saber social particular. Simplemente, lo que se quiere mostrar es la continuidad y prolongación que las prácticas sociales (histórico-culturalinterpersonal-privadas y ético-políticas) adoptan los campos sociales en los que se expresa el sujeto y cómo dichas prácticas y campos a su vez son recogidos en los lineamientos de ciencias sociales. De esta forma, hemos querido adelantar pistas, abrir ventanas, otear horizontes para una educación social, que realmente recupere el sentido de la paideia griega, en donde la verdad (los saberes) la justicia (equidad) y la belleza (el sujeto creador) sean devueltas a la escuela.

\section{Referencias bibliográficas}

DOGAN, M.; PAHRE, R., Las nuevas ciencias sociales y la marginalidad creadora, Grijalbo, México, 1993.

GARCIA CANCLINI, Néstor, Culturas híbridas. Estrategias para entrar y salir de la modernidad, Consejo Nacional para la Cultura y las Artes, Grijalbo, México, 1989.

GÓMEZ E., Jairo H., La construcción del conocimiento social en la escuela, Bogotá, Universidad Distrital, Centro de Investigaciones, Capítulo III, 2002.

JAEGER, W., Paideia: los ideales de la cultura griega, Fondo de Cultura Económica, México, 1992.

MEN, Serie Lineamientos curriculares ciencias sociales, Bogotá, 2002.

OLIVÉ, L., La explicación social del conocimiento, UNAM, México, 1994,

RAWLS, J., Teoría de la Justicia, Fondo de Cultura Económica, México, 2000.

REMMLING, G., Hacia la Sociología del Conocimiento, Fondo de Cultura Económica, México, 1986. 